\title{
O QUE PENSAM OS PROFESSORES SOBRE A FUNÇÃO DA AULA EXPOSITIVA PARA A APRENDIZAGEM SIGNIFICATIVA
}

\author{
What teachers think about the function \\ of the expository class for meaningful learning
}

\author{
Jesuína Lopes de Almeida Pacca ${ }^{1}$ \\ Anne Louise Scarinci ${ }^{2}$
}

\begin{abstract}
Resumo: Professores são convidados a introduzir uma aula expositiva numa sequência didática planejada. Os professores tiveram bastante dificuldade para localizar a atividade dentro do que concebiam sobre ensino e aprendizagem significativa. Diante da tarefa proposta, procuraram sistematizar os conteúdos anteriormente desenvolvidos na sala de aula, atribuindo novo sentido à estratégia, sem abandonar a importância de ouvir o aluno e de articular adequadamente os conceitos. A aula expositiva de cada um foi ressignificada, aparecendo com posição definida na sequência pedagógica e com conteúdo significativo em relação ao nível de conhecimento do aprendiz. A conclusão fundamental foi que, mesmo sem ser explícito, era possível haver diálogo entre os saberes do professor e dos alunos, o que parece ter ocorrido também com os professores enquanto aprendizes no programa de formação.

Palavras-chave: Construtivismo na sala de aula. Aula expositiva construtivista. Aprendizagem significativa. Formação de professores.
\end{abstract}

\begin{abstract}
Teachers from a professional development program were invited to introduce expository classes (lectures) inside a pedagogical sequence they had planned. Classes were analyzed with criteria seeking to situate them within constructivist conceptions of teaching practice. The teachers had considerable difficulties in locating the activity into what they understood as teaching and meaningful learning. Facing the task proposed, they sought to make a systematization of contexts previously developed in the classroom, attributing new meaning to the strategy without abandoning the importance of listening to the learner and adequately articulating concepts. The expository class was given a new meaning, appearing with a defined position in a pedagogical sequence and a meaningful content in relation to the apprentice's level of knowledge. The most fundamental conclusion was that, even if not explicitly, it is possible to have dialogue between the teacher's and students' knowledge. This seems to have also occurred with the teachers themselves while learners in the teacher education program.
\end{abstract}

Keywords: Constructivism in the classroom. Constructivist expository class. Meaningful learning. Teachers' education.

${ }^{1}$ Licenciatura e Bacharelado em Física, doutora em Educação. Docente, Instituto de Física, Universidade de São Paulo (USP). São Paulo, SP, Brasil. <jepacca@if.usp.br>. Bolsa de produtividade do CNPq.

${ }^{2}$ Licenciatura em Física, doutora em Educação. Bolsista CNPq. São Paulo, SP, Brasil. <1.scarinci@gmail.com>. Apoio CNPq.

${ }^{1}$ Universidade de São Paulo, Instituto de Física

Rua do Matão, Travessa R, 187 - Edifício Basílio Jafet

Cidade Universitária - São Paulo, SP

05.508-090

709

Ciência \&̊ Educação, v. 16, n. 3, p. 709-721, 2010 


\section{Introdução}

Quando os professores frequentam um curso procurando melhorar seus resultados com a aprendizagem na sala de aula, abre-se oportunidade para desenvolverem um olhar mais crítico e analítico sobre sua prática e procurarem novas formas de ensinar, capazes de atingir mais precisamente suas metas de ensino. A própria concepção do que deva ser esse 'alvo' pode mudar, num processo de análise da prática cotidiana.

Apesar de enxergar com um pouco mais de clareza quando um resultado de aprendizado é ou não satisfatório, o que os professores nem sempre conseguem é saber o que produziu esse resultado e, consequentemente, que estratégias e atitudes adotar ou recusar, para, na continuidade das suas aulas, aproximar os resultados à meta almejada. Desta forma, se um professor frequenta um curso para, então, aplicar os novos conhecimentos na sala de aula, podem surgir problemas que ele não sabe resolver sozinho, e maiores são as chances de abandono da tentativa de mudança e retorno ao solo firme da prática com que estava habituado (PACCA, 1992).

Os professores em exercício já detêm uma prática pedagógica que, de algum modo, vem funcionando; não atingindo plenamente os objetivos de ensino de forma satisfatória e desejável, mas garantindo, ao professor, segurança quanto à sequência didática a ser adotada, à previsibilidade de respostas dos alunos às atividades, aos métodos de avaliação e às necessidades de improvisação que possam surgir na sala de aula. Um programa de formação que se dedica ao aperfeiçoamento docente e à modificação, de fato e com profundidade, dessas práticas dos professores, precisa atender às necessidades de coerência e continuidade daquilo que eles já fazem cotidianamente nas suas intervenções de ensino, além de dar amparo às inseguranças, dúvidas e problemas que, certamente, surgem no percurso.

Por isso, a modificação substancial de uma prática profissional raramente é conseguida com um curso em que se transmitem, simplesmente, as novas teorias - sejam os conteúdos específicos, sejam as metodologias a serem aplicadas na sala de aula. Como parte do curso, é preciso questionar as "habilidades e recursos que refletem as capacidades pessoais com respeito à prática de ensino, ao conhecimento ministrado ou às pretensões educativas" (CONTRERAS, 2002).

Desta forma, mais do que simples cursos, é necessário pensar em programas que disponham de espaço para a exposição e discussão das hipóteses e tentativas dos professores que põem em prática novas ideias. Ao trazer para um espaço de formação profissional as situações ocorridas e discuti-las com seus pares e com o formador, à medida que relata suas atuações em sala de aula e as contrapartidas vindas dos alunos, o professor consegue colocarse na posição de pesquisador de sua prática, no sentido da pesquisa-ação exposto por Zeichner (2000), pois as verbalizações de fracassos e sucessos passam a pedir explicações e elaboração de hipóteses sobre a atuação, que podem ser testadas e analisadas.

Em equipe, os professores conseguem fazer muitas descobertas de natureza tácita, que dão vida e fazem interagir o discurso teórico aprendido com todo o conjunto de atividades e iniciativas práticas necessárias ao cotidiano da sala de aula. Conseguem, então, formular uma nova estrutura conceitual coerente e aplicável, com possibilidade real de mudança no conjunto de hábitos de ensino, mesmo que não necessariamente definitiva.

De fato, ao mudarmos um conjunto de práticas, não descartamos totalmente os procedimentos anteriores, e há, pelo menos, dois bons motivos para isso. O primeiro é que 
O que pensam os professores sobre a função da aula ...

não podemos jogar fora o conhecimento que dominamos em favor de outro incerto e que ainda não sabemos bem. Segundo, que nem todos os aspectos do conhecimento anterior são inválidos. A questão é: quais aspectos preservar? - e que novo sentido dar a eles para que se tornem coerentes com a nova base teórica? - e quais devem ser, de fato, descartados ou modificados substancialmente?

Assim como os alunos, os professores também têm pré-concepções, não somente quanto ao conteúdo científico, mas também quanto à visão de ciência e à visão de ensino e aprendizagem; e suas concepções são basicamente tão limitadas quanto as visões e ideias dos alunos nos mesmos domínios. Quando professores se engajam em um programa para aprender estratégias de ensino ditas construtivistas, trazem suas concepções do que seja ensino e do que seja construtivismo; e, da mesma forma que se preconiza com alunos, essas concepções devem ser consideradas, questionadas com reflexões pessoais e circunstanciadas no ambiente escolar, para que ocorra uma mudança efetiva.

O construtivismo já foi considerado e usado como um antídoto a todas as estratégias de cunho "tradicional" e, ainda hoje, quando se fala em ensino construtivista, uma série de pré-concepções são invocadas para definir o que pode e, sobretudo, o que não pode ser feito numa situação de ensino. Isto porque tal situação envolve sempre uma intervenção e, nessa expectativa, não se admite intervenção (LABURÚ; ARRUDA, 2002).

Sempre associado à epistemologia piagetiana, o que os professores procuram fazer é levar para a sala de aula atividades bastante operacionais que exijam manipulação, observação e conclusões sobre os fenômenos em questão. A operacionalidade intelectual, sem que explicitamente declarado pelo professor, é quase sempre menosprezada ou esquecida. De fato, Piaget nunca propôs uma pedagogia associada à sua teoria, mesmo porque essa associação seria completamente incoerente com seus pressupostos teóricos. O controle sobre a dinâmica dos processos de aprendizagem que poderia levar a uma prática pedagógica definida cientificamente é impossível, se pensarmos que a própria construção do conhecimento, como entendida por Piaget, baseia-se na atividade do sujeito à medida que enfrenta conflitos e erros que são imprevisíveis e não padronizáveis. Num artigo que trata da instrumentação prática do construtivismo, Lajonquière (1992) destaca a característica necessária de arte e improvisação da atividade pedagógica, e a impossibilidade de sua racionalização e determinação. É desse construtivismo que tratamos aqui e que é capaz de levar a uma aprendizagem significativa, isto é, que corresponde a uma construção efetiva de arcabouços mentais para se entender determinado conteúdo.

Tendo em vista essas preocupações, estudamos o desenvolvimento de um grupo de professores que participam de um programa de formação contínua orientado por uma equipe formadora que acompanha os relatos das aulas de cada um, estabelecendo uma discussão entre todos os participantes; o interesse do programa é promover e estudar mudanças na prática de sala de aula para um aprendizado significativo dos alunos. Com esse objetivo, o professor planeja e aplica contextos e situações que levem os alunos a construírem seu conhecimento. A aula expositiva vem localizada no corpo geral de um planejamento e é capaz de estabelecer uma situação perfeitamente adequada dentro de um processo de construção do conhecimento. Macedo (1994), ao tratar do construtivismo na prática pedagógica, refere-se à explicação verbal - situa o que ocorre numa aula expositiva - afirmando que "a explicação verbal é importante na prática pedagógica. Ser construtivista não é ser contra a linguagem, mas tratá-la de um outro ângulo" (MACEDO, 1994, p. 36). 
Durante o percurso, naturalmente os professores encontram dificuldades e problemas, tanto na escolha e aplicação das atividades planejadas, como na compreensão dos retornos da aprendizagem dos alunos. Alguns desses problemas, para eles, já existiam antes e ficam visíveis agora pelo exercício do olhar mais atento ao que acontece na sala, sob incentivo do formador; outros são novos e decorrem de uma transposição teoria-prática ainda imatura ou não bem ajustada.

É notório o fato de que os professores, diante de um programa com essas características, eliminam, das suas aulas, a "aula expositiva", concebida por eles como anticonstrutivismo. Isso nos sugeriu investigar, de modo concreto e objetivo, as razões desse comportamento. Por isso, nosso foco na atuação desses professores colocou-se em uma das estratégias que eles utilizaram em sala de aula a partir de uma proposta explícita do formador - uma aula expositiva depois de um período em que vários conceitos haviam sido tratados em aulas com diferentes atividades planejadas e que sugeria um "fechamento" teórico/formal. Após a surpresa inicial dos professores com a solicitação do formador, aceitaram o desafio que representava uma atividade desse tipo para quem pretendia ser construtivista. Foi assim que pensamos observar a atuação dos professores ao planejarem e organizarem uma aula expositiva dentro da sequência didática em desenvolvimento: analisar os problemas e dificuldades com os quais se depararam, as maneiras encontradas para solucioná-los, e a forma como o surgimento e a superação desses obstáculos os impulsionou na construção do conhecimento sobre a prática construtivista na sala de aula.

\section{Desenvolvimento da pesquisa}

\section{O grupo de professores e as atividades}

Analisamos os relatos de aulas de professores de física do Ensino Médio, da cidade de São Paulo. Esses professores são os participantes de um grupo de estudos em modalidade formação continuada no Instituto de Física da Universidade de São Paulo ${ }^{3}$. Os relatos espontâneos são fonte de dados privilegiada quando se trabalha no contexto do construtivismo, por serem mais fiéis à concepção dos indivíduos dentro do contexto de interesse. Dispondo de grande volume de relatos em gravações regulares das seções de discussão do grupo, não consideramos outras fontes de dados.

O projeto desenvolvido com os professores (dez, ao todo), cujo material foi estudado, esteve em curso no ano de 2005 e teve o objetivo de aprimoramento no ensino (desenvolvimento de materiais, estratégias, atitudes e competências pedagógicas), bem como de aprofundamento conceitual em física, dentro do tema específico do eletromagnetismo. Todos os professores participantes estavam lecionando esse conteúdo e construíram os planejamentos

\footnotetext{
${ }^{3}$ Projeto "Eletromagnetismo no Ensino Médio: barreiras conceituais e estratégias de ensino", apoiado pela FAPESP, dentro do programa para Melhoria do Ensino Público.
} 
O que pensam os professores sobre a função da aula ...

para isso, com o acompanhamento do formador e de uma equipe de três pós-graduandos em Ensino de Ciências.

Como parte das atividades, os professores elaboraram um planejamento de aulas, que aplicaram com os alunos (planejamento que pôde ser modificado ao longo do curso, conforme surgimento de novas necessidades e resultados de aprendizagem) e fizeram constar, explicitamente, os objetivos de ensino para cada etapa desse planejamento.

O grupo estabeleceu, para o primeiro semestre de curso, o estudo da eletricidade com ênfase na compreensão aprofundada do conceito de corrente elétrica em âmbito macroscópico tanto quanto microscópico. Embora esse eixo principal tenha sido consensual entre os professores, as sequências pedagógicas traçadas não foram coincidentes, mesmo apresentando várias semelhanças por conta do compartilhamento constante estabelecido durante os encontros de formação.

Nas reuniões semanais do grupo, havia um momento para que os professores relatassem e comentassem as atividades que desenvolveram com os alunos durante a semana. Eles sempre tinham a tarefa de fazer observações e registros de ocorrências relevantes das aulas regulares que ministravam nas escolas, como expressões significativas ou dificuldades dos alunos. Os relatos orais a partir dessas observações foram gravados em áudio e constituíram a nossa principal fonte de dados.

\section{A sequência pedagógica}

A sequência pedagógica desenvolvida pelos professores corresponde a um planejamento de aulas, que, no nosso caso, está sempre em re-elaboração, porque leva em conta os resultados da aplicação contínua em sala de aula.

Dessa forma, apresentamos, no Quadro 1, uma sequência que não necessariamente espelha o grupo todo, mas que sintetiza e dá conta da maioria das atividades que os professores desenvolveram com os alunos (mesmo que não exatamente nesta ordem), e que servirá aos nossos propósitos no momento, com foco naquilo que os professores apresentaram na aula expositiva, ao fim desse conjunto de atividades.

Quadro 1. Atividades pedagógicas desenvolvidas para o ensino da corrente elétrica.

- Conversa sobre usos e pertinência da eletricidade.

- Montagem, em grupos, de circuito pilha-lâmpada e discussão / atividades para explicar "Por que a lâmpada acende".

- Análise da estrutura física de uma lâmpada - ênfase nos condutores de eletricidade.

. Desenhos do átomo (a título de levantamento de pré-concepções).

- Leitura de textos sobre modelos atômicos.

- Pesquisa sobre a estrutura da matéria - com o objetivo de entender a estrutura cristalina do fio condutor.

- Ligação metálica e elétrons livres.

- Experimentos de eletrização - eletrostática. Compreensão de elementos condutores e isolantes. Conceito de carga elétrica.

- Análise da composição e do funcionamento de uma pilha.

- Esquematização do circuito fechado pilha-lâmpada.

- Aula expositiva de fechamento e síntese dessa etapa. 
Em seguida a essa sequência, os professores fizeram uma avaliação e tinham a intenção de continuidade com o estudo dos circuitos em série e em paralelo. As avaliações realizadas trouxeram resultados muito significativos e que os fizeram repensar a sequência aplicada, as formas de condução das aulas e as interações com os alunos.

Os professores não haviam planejado a aula expositiva a priori e, muito menos, tinham a intenção de incluir tal atividade em suas aulas. Essa foi uma determinação do formador, que percebeu a necessidade e a falta de uma atividade sintetizadora nos planejamentos, que servisse para organizar o conteúdo físico estudado até esse momento. A repulsa dos professores a esse tipo de instrumento pedagógico, quando o formador anunciou que daria uma aula expositiva, foi também sugestiva porque revelou uma pré-concepção que devia ser enfrentada.

\section{A inserção da aula expositiva na sequência pedagógica e na sala de aula}

Como os professores iriam planejar essa aula e como analisariam a devolutiva dos alunos à "novidade"? Nosso objetivo era focalizar o professor na sua prática pedagógica a partir do que eles produziam e da análise da sequência tratada na sala de aula.

Para esta análise, escolhemos a parte da sequência em que o professor planejou a "aula expositiva", que, dentro do contexto, tinha a intenção de sistematização do estudo da corrente elétrica. Essa atividade exigiria do professor conhecimento mais aprofundado do conteúdo e também das dificuldades dos alunos dentro desse conteúdo. Cada participante (identificado, neste texto, por duas letras maiúsculas, como PA, ZE, MO) elaborou um plano diferente para a aula expositiva, o que mostrou a sua concepção sobre essa atividade e o conteúdo visto com enfoques particulares e pessoais.

Como a necessidade de uma aula expositiva fora apresentada pela formadora durante uma reunião do grupo, alguns professores simplesmente planejaram e aplicaram a aula, sem muito cuidado ou preocupação em situá-la e articulá-la no conjunto das atividades do planejamento. Isso já revela uma carência de significado sobre o construtivismo contido num planejamento pedagógico, bem como sobre a função de uma aula expositiva.

Outros manifestaram claramente uma preocupação quanto ao momento mais apropriado de trazer, para os alunos, a síntese científica do conteúdo. Essa preocupação traz consigo informações sobre o que os professores consideram ser a função de uma aula expositiva e de uma abordagem construtivista de ensino. Transcrevemos, a seguir, um comentário de PA, em um encontro posterior, ao de ter ficado "felicíssima" com a ideia de apresentar uma aula expositiva como síntese do estudo.

"Eu ia começar a aula expositiva e não tive coragem. Eles não estavam no ponto que eu queria". PA apreciou a ideia de dar um fechamento ao conteúdo, planejou uma aula para tal e, no momento de aplicá-la, desistiu. Sua percepção de que um "ponto ótimo" para a intervenção ainda não havia sido alcançado denotou uma concepção de aula expositiva como momento de exposição de ideias já discutidas e, de certa forma, já encaminhadas ou resolvidas pela classe. ZE expressa uma ideia similar: "[Uma aula expositiva pode] dar a impressão de estar jogando fora tudo o que nós trabalhamos até agora. Mas eu acho que essa sintese só acontece depois de os alunos já terem discutido os conceitos mais básicos."

O sentimento de precocidade da explicação parece ter surgido porque os alunos não tiveram contato com todos os conceitos que o professor pretendeu usar na aula expositiva; 
O que pensam os professores sobre a função da aula ...

mas, talvez, tomar contato com um conceito não basta, a saber pelo termo "terem discutido" usado por ZE nesse caso, que provavelmente quis dizer "terem compreendido", como se uma aula expositiva não pudesse contribuir para aperfeiçoar tal compreensão.

$\mathrm{O}$ adiamento de uma aula de fechamento também pôde ocorrer devido a uma noção individualizada de construção do conhecimento. A aula expositiva, dentro dessa concepção, deveria esperar que cada aluno chegasse ao "ponto ótimo". A fala de SU, sobre uma aula expositiva dada por outra professora, "[a aula] não levou em consideração o ponto em que cada aluno está", nos permite o entendimento de que, para ela, o professor deveria esperar todos construírem os conceitos por completo antes que pudesse fazer uma síntese dos conteúdos - ou quiçá, de que uma aula expositiva não devesse acontecer, por ser uma forma de explicação que, ao almejar o coletivo, não atinge o individual. De fato, no entendimento de SU, a aula expositiva não caberia em um planejamento construtivista, porque não serviria para ajudar a construir o conhecimento ainda insuficiente.

Vale notar que, ao mesmo tempo em que os professores esperavam os alunos chegarem num ponto adequado, contavam que estes estavam impacientes por uma formalização. $\mathrm{RE}$, por exemplo, relatou que os alunos pediram por fórmulas matemáticas. $\mathrm{MO}$ falou que "Os alunos reclamam de falta de material escrito na lousa".

Nenhuma dessas professoras relacionou prontamente esses pedidos dos alunos com a premência de uma aula de sistematização, em que o professor expusesse os conhecimentos científicos esperados. RE interpretou a fala dos alunos como uma expectativa de caráter préconceitual, de que a física, para os alunos, deveria conter muita matemática; MO defendeu seus procedimentos metodológicos de não fazer uma sistematização do conhecimento na lousa dizendo que "[os alunos] devem ter o conbecimento na cabeça".

RO também comentou manifestações das suas classes nesse sentido, mas pôde compreender melhor a necessidade de seus alunos, pois estes foram mais explícitos ao pedirem que "nessa aula eu não firesse perguntas e falasse o conteído".

Ao adotar a atitude construtivista de prever um tempo para que o aluno construa o conhecimento, os professores ficam inseguros quanto ao tempo de espera e aos indícios de que esse tempo fora atingido. Um dos exemplos é esta fala de HE: "estou em dúvida de quanto tempo esperar para que o aluno chegue ao conceito sozinho, e quando o professor deveria intervir”. Na reunião seguinte, HE parece ter encontrado parte da resposta, relacionando com sua trajetória pessoal no aprendizado da eletricidade: "Esse conteúdo] eu não iria pensar sożinha mesmo. Então algumas coisas o aluno também não vai conseguir sozinho".

HE ficou muito feliz ao ministrar sua aula expositiva, relatando que os alunos "ficaram em absoluto silêncio, prestando muita atenção e anotando tudo, o que é bastante incomum”. Para ela, a aula foi dada no momento certo.

Pensando sobre reclamações dos alunos de "muito conteúdo de uma vež só", SI elaborou a hipótese de distribuir os momentos de sistematização por várias aulas, em vez de uma única aula de síntese. Contudo, SI não trouxe indícios explícitos dos seus alunos, se eles também achavam que fora muito conteúdo. Talvez a professora, por não estar acostumada com esse tipo de aula, tenha sentido que foi muito trabalho para ela.

O momento oportuno parece ser um dos fatores que favorecem a ressignificação da aula expositiva e sua inserção num ensino coerente com concepções construtivistas da aprendizagem; diz respeito ao sentimento dos professores e, também, dos alunos, segundo o relato dos 
professores, de pertinência da aula ao estágio em que os alunos estariam, no processo de construção dos conceitos envolvidos. O professor pode ter sentido que sua intervenção ocorreu precocemente, tardiamente ou no momento certo. O professor também relata que manifestações vindas dos alunos o ajudaram a avaliar o momento oportuno da intervenção. Isto é, o professor considera o feedback dos alunos para conduzir sua exposição e, eventualmente, replanejá-la, como aparece nos relatos. São posturas coerentes com o construtivismo e que permitirão reconsiderar uma aula expositiva quando está em jogo a aprendizagem significativa.

Como a aula expositiva idealizada por todos os professores não teve a intenção de abertura, mas de conclusão do assunto estudado, a expectativa, em geral, foi a de que, a partir dela, os alunos chegassem a uma compreensão "final" do conceito de corrente elétrica e dos fenômenos envolvidos, e que quaisquer possíveis dúvidas fossem esclarecidas.

De fato ainda não estava clara a ideia de que uma aula expositiva pudesse ser um instrumento facilitador de estruturação de ideias ainda pouco amadurecidas. Nessa outra concepção, a aula expositiva poderia estar num nível um pouco acima daquilo que já fosse dominado pelo aluno e poderia reestruturar, com sua estrutura organizada, o conhecimento em construção.

No entanto, o formato que essa aula deveria tomar para atingir tais objetivos variou em relação ao que os professores imaginaram que uma aula deveria ter para manter coerência com a linha pedagógica idealizada e com as estratégias anteriores desenvolvidas na sala de aula. Percebemos aulas em que o professor:

- Descartou o que foi construído pelos alunos em fase anterior;

- Esperou que os alunos chegassem às questões, de modo que a aula expositiva as respondesse;

- Esperou que os alunos construíssem as questões e as respostas científicas, de modo que a aula fosse uma síntese dos conhecimentos já sabidos.

- Apenas detectou as pré-concepções e as expôs em aulas expositivas, comparando dizeres dos alunos com o conhecimento cientificamente estabelecido.

Vale à pena retomar um pouco o que foram as manifestações dos participantes quando o formador propôs a aula expositiva como estratégia possível nos seus planejamentos. $\mathrm{O}$ que se observou, por parte da maioria dos professores, foi uma reação inicial de repulsa à ideia, como se ela representasse uma traição aos pressupostos teóricos e metodológicos que o grupo estava seguindo. Nas suas concepções, realmente numa abordagem construtivista, a aula expositiva e formalizadora de conceitos estaria banida (ZE: "para mim deu a impressão de estar deslocado"), de forma que os professores se assustaram quando a formadora, deliberadamente, ministrou uma aula, com todo o conteúdo, as formulações matemáticas e os termos científicos, como exemplo do que poderia ser feito. SU comenta: "Então por que levamos tanto tempo para chegar ao conceito de corrente elétrica? Poderíamos ter olhado o livro, mas a idéia não era essa, era de construirmos o conceito".

Essa fala de SU claramente expressa sua ideia de que, em uma abordagem construtivista, a aula expositiva não seria uma estratégia coerente, pois os conceitos seriam construídos pelos alunos até sua formalização científica final. RE também ponderou a respeito, tentando, contudo, encaixar a nova ideia como razoável dentro da sua estrutura teórico-pedagógica: " $A$ gente fica assustado porque foi uma aula diferente do que estamos acostumados, foi uma aula mais tradicional. Mas eu senti que é importante parar e falar sobre aquilo." 
O que pensam os professores sobre a função da aula ...

No caso, "diferente do que estamos acostumados", nas palavras da RE, pode significar diferente do que estamos tentando construir como novo paradigma pedagógico, pois certamente os professores todos já foram muito acostumados com aulas expositivas, somente que talvez não dentro desse pensar pedagógico em que o aluno deve ser ativo em seu aprendizado. Aqui entra outra pré-concepção sobre metodologias construtivistas, em que a "atividade" do aluno é vista somente como atividade motora, de manipulação de materiais, ou verbal, de discussão, mas não mental e abstrata, de interpretação de um fenômeno ou reflexão sobre uma teoria que está sendo apresentada.

A aula expositiva faz parte de um imaginário de muitos anos nos bancos escolares, então nada mais natural que os professores se reportem àquelas aulas que tiveram, ao tentar planejar tal estratégia. Talvez justamente pela familiaridade, através de vários anos de experiência como aluno (e, também, como professor), com o "jeito tradicional de dar aulas", alguns professores, após várias aulas concebidas por eles como construtivistas, retornaram à metodologia tradicional na sua aula expositiva de fechamento. NA comentou que os alunos ficaram frustrados (ou será que foi ela que ficou frustrada?): "Fiz a sintese e eles ficaram com a idéia que tudo o que fizeram nas aulas anteriores estava errado e deveria ser jogado fora."

A aula de NA deixou a impressão, para ela (e para os alunos?), de que as atividades anteriores haviam sido inúteis. Talvez muito mais para ela do que para os alunos, fruto de seus conceitos conflitantes entre aula expositiva e construtivismo.

Para que servem as aulas anteriores à aula expositiva? Para nada, tal qual a sensação de NA e seus alunos? Poder-se-ia, então, perguntar se não bastaria que o professor ministrasse, logo de início, aulas expositivas. A dúvida não ocorreu para todos; mas diante do desconforto instaurado, os professores buscaram, nas suas experiências como alunos, alguma interpretação dos resultados.

Houve consenso, no grupo, de que algum tempo dado ao aluno, reservado para a construção do conhecimento, é de fato necessário. Três professores traçaram comentários a partir de um curso de astronomia de que participaram: em um dos tópicos, a ministrante, por falta de tempo, apenas esperou que os alunos construíssem as dúvidas, e, em seguida, deu uma aula com as respostas da ciência. Avaliaram que esse tópico de ensino, por conta do tempo menor para pensar e construir um raciocínio sobre o fenômeno, ficou mais confuso e menos compreendido pelos participantes, quando comparado aos outros tópicos em que a ministrante designou mais tempo para as atividades-meio, como discussões, modelagens etc.

Um comentário de RO, em outra ocasião, também reflete a relevância desse tempo: "O aprendizado se dá quando o aluno reconbece o pensamento dele dentro do contexto. Porque comigo é assim. Aqui, quando eu não falo, mais depois reconheco as idéias que eu tive em alguma fala, faço conexões, aprendo.” A conclusão da professora foi que, para que o aluno reconheça suas ideias na fala do professor durante a aula expositiva, o professor deve designar tempo em aulas anteriores, suficiente para o florescimento dessas ideias.

Alguns professores gostariam que, somente através das atividades de investigação (por exemplo, aulas práticas e de exercícios), os alunos elaborassem todo o conhecimento científico, e esperavam esse momento (que nunca chegava) para que pudessem passar à aula expositiva de fechamento - que, esta, de modo algum, conteria novidades.

SU comentou, com impaciência, que seus alunos não chegavam por si próprios ao conceito de carga elétrica. Através de intervenções somente no sentido de provocação, SU que- 
ria ouvir dos alunos a conceituação da corrente elétrica como sendo composta de cargas em movimento, embora eles falassem de algo (não usando a palavra carga, mas outras como energia ou força) que se movimentava através do fio condutor: "Se eles não falam em carga elétrica, se não chegam à palavra carga, então eles ainda não chegaram lá, como é que eu vou continuar?"

A dúvida sobre o que a aula expositiva deveria conter das ideias do aluno e em que deveria complementar essas ideias perpassou por várias falas dos professores. De HE, por exemplo, "Não está bem claro o que eu posso esperar do aluno e o que não posso esperar dele, e que en vou ter que falar para ele."

Ou seja, percebemos um impasse sobre qual deveria ser o conteúdo de uma aula expositiva, até que ponto deve conter ideias construídas pelos alunos e quanto deve conter de novidades, de complementação às ideias estudadas em aulas anteriores.

Uma análise da qualidade da intervenção parece ser outro fator que facilita uma ressignificação da aula expositiva; descreve como essa atividade foi realizada e percebida pelos professores e seus alunos. O professor relata qual foi a sua ideia com aula, que funções ele esperava que essa aula desempenhasse em relação ao conjunto das atividades realizadas, e por que escolheu determinado eixo condutor para a apresentação da aula.

O que os professores perceberam e ouviram dos seus alunos foi bastante variado, como: reclamações de excesso de informações, manifestações de entusiasmo, frustrações, grande concentração etc. Isso tudo levou à reflexão sobre o planejamento como um todo e a inserção da aula expositiva adequadamente.

Certamente, essas dimensões, em alguma instância, se interpõem, pois, de fato, a qualidade e o momento de uma intervenção estão intimamente relacionados. A escolha do momento pode ser fruto de uma determinada concepção e objetivos da aula visualizados pelo professor; e se uma aula não surtiu o efeito esperado, não é descabido que o professor possa atribuir, como um dos fatores de fracasso, a inadequação do momento em que a aula ocorreu.

As dúvidas geradas quanto ao momento oportuno e ao conteúdo da aula expositiva guardam, também, conexões com o domínio do conteúdo específico da física por parte do professor. Ele percebe que não sabe quando ou como continuar porque ele também não domina conteúdo em profundidade. No exemplo de SU, dado anteriormente, como para a própria professora a ideia de carga elétrica não estava clara, ela não conseguia perceber os indícios da construção desse conceito na fala dos alunos. A verbalização de HE, citada em seguida, é uma insegurança da mesma natureza.

\section{Conclusões}

Os professores que se inscreveram para participar deste programa de formação tinham intenções claras e declaradas de melhorar seus conhecimentos e estratégias de ensino, e estavam dispostos e ansiosos por testar novas abordagens pedagógicas dentro da linha do construtivismo.

No início das atividades do grupo, foi pedido que cada professor definisse um objetivo de ensino, que seria o eixo condutor das atividades sobre o tema da eletricidade, e que a partir dele elaborasse um planejamento de aulas com atividades capazes de levar os alunos à compreensão daquele objetivo. 
O que pensam os professores sobre a função da aula ...

Nas reuniões do grupo, o conteúdo de eletricidade também era discutido pelos professores, com base nas necessidades de seus planejamentos e das dúvidas que surgiam ao levar as atividades para a sala de aula, questões colocadas pelos alunos etc. Com uma compreensão maior sobre a eletricidade e um retorno constante dos alunos, o planejamento podia ser alterado.

No entanto, a compreensão dos professores sobre estratégias de ensino coerentes com a linha metodológica adotada também estava sendo construída. Inicialmente, muitos professores não fizeram constar, de seus planejamentos, aulas expositivas, e ficaram muito surpresos com a possibilidade explicitada (e, mais tarde, exemplificada) pela formadora.

Ficou evidente o pré-conceito dos professores em relação à "aula de giz e lousa". $\mathrm{Na}$ sua ideia sobre o construtivismo, em todas as atividades planejadas, havia a necessidade de constante interação explícita com os alunos. Aliado a isso, havia ainda o pressuposto de que, numa aula expositiva, a interação e a participação do aprendiz não ocorrem.

Essa pré-concepção que o professor traz sobre aulas construtivistas pode implicar sérias dificuldades para sua atuação, porque ele elimina, do planejamento, a sistematização dos conteúdos. No programa de formação de professores que acompanhamos para este trabalho, essa dificuldade veio à tona conforme as aulas eram ministradas, quando alguns professores sentiram dúvidas sobre as possibilidades reais de seus alunos chegarem, apenas com as atividades de discussão e investigação, ao conhecimento científico - com o grau de formalização necessário e esperado. Ou, então, traziam indicativos vindos de cobrança dos alunos, externalizada em reclamações por "algo escrito" ou por respostas às tantas questões geradas em várias aulas.

Os professores não se contentaram com as descobertas e aproximações parciais conseguidas pelos alunos, ou seja, seus objetivos quanto ao aprendizado do conteúdo não afrouxaram pela escolha do enfoque construtivista. Porém, talvez pela compreensão ainda incipiente do que é possível em sala de aula dentro da linha construtivista, desconsideraram a aula expositiva - a exposição das ideias científicas na sua versão formalizada, matematizada e organizada logicamente - como uma ferramenta para alcançar essa meta. E alguns, ingenuamente, esperavam que essa formalização fosse descoberta dos alunos.

$\mathrm{Na}$ verdade, essa dificuldade surgiu, em grande parte, da busca de coerência, por parte dos professores, quanto ao conjunto de estratégias a escolher, pensando na nova base conceitual em desenvolvimento. Eles sabiam que, ao adotarem uma nova opção teórica e metodológica, não poderiam aplicar a aula expositiva da mesma forma que antes. Pelos relatos, pudemos perceber um grande movimento pela busca de um novo sentido para a estratégia.

Ao ministrarem as aulas expositivas, alguns relatos delataram a falta de conexões suficientes entre o conhecimento científico exposto pelo professor e aquele ao qual os alunos foram capazes de chegar. Outros conseguiram uma boa conexão com as ideias dos alunos, mas não sistematizavam as ideias científicas a contento.

Algumas aulas expositivas tardaram por esperar que os alunos chegassem ao conceito, ou por esperar que todos os alunos alcançassem certo estágio na construção do conceito, enquanto outros professores se impacientaram e contaram logo o "fim da história".

O equilibrio entre uma postura mais centralizadora no professor e uma mais permissiva é difícil de se conseguir. Se imaginarmos um segmento de reta com extremidades nos dois polos, podemos imaginar professores situados em várias posições em torno do centro desse segmento e, ainda, algumas aulas de um mesmo professor tendendo mais para um ou para outro lado. 
Assim, poderíamos classificar as intervenções dos professores igualmente de outro modo - as que se aproximaram mais das pedagogias em terceira pessoa (tradicionais, foco no professor) e as que penderam para as pedagogias em primeira pessoa (foco no aluno). Porém mais interessantes foram a análise e os aprendizados que os próprios professores elaboraram a partir da vivência e da re-visão do construtivismo, diante da necessidade de inclusão de uma estratégia de aula que, inicialmente, viram como totem de um ensino diferente daquele em que acreditavam.

Nesse processo, os professores puderam reafirmar a necessidade de ouvirem atentamente o aluno - pois uma aula expositiva só consegue ser comunicada ao aluno se a ideia deste encontra alguma ressonância na fala do professor - e é o professor quem é mais capacitado para fazer essa conexão. Também perceberam que um planejamento que está linear na cabeça do professor não é visto dessa forma pelos alunos - estes não enxergam a pertinência desta ou daquela atividade para a sequência - e, também, cabe ao professor explicitar a articulação entre as atividades e os conceitos estudados.

E como aprendizado, talvez, mais fundamental, os professores compreenderam que trabalhar de forma construtivista em sala de aula exige intervenções deliberadas por parte do professor. Redescobriram o papel importante e imprescindível do professor, não só para estimular o pensamento do aluno e proporcionar as atividades instigantes que preencham as partes do quebra-cabeça da ciência, mas também de trazer essa ciência em sua versão formalizada, estabelecendo as conexões entre as várias atividades que os alunos realizam e complementando o conhecimento que os alunos foram capazes de construir.

É interessante notar que nem sempre o momento oportuno foi ponderado de antemão e, também, nem sempre a consciência desse momento foi claramente expressa pelo professor, sendo, muitas vezes, uma interpretação nossa a partir dos relatos, e uma observação que o formador fez ao grupo. A qualidade que deveria ter a aula tampouco foi uma construção autônoma: alguns professores pensavam que bastaria uma síntese das ideias desenvolvidas pela classe, e outros tinham mais clareza de que deveriam mostrar a ciência formal, mas não sabiam conectar essa aula com as demais atividades de construção. A própria ideia da aula expositiva também não partiu dos professores.

Assim, como consideração adicional, notamos que, exatamente como aconteceu com os alunos, os professores também precisaram de alguém para sistematizar suas conquistas, dúvidas e conflitos não resolvidos, e para complementar os conhecimentos alcançados dentro de uma visão mais ampla e formalizada da teoria do construtivismo e das suas possibilidades de aplicação na sala de aula.

Se compararmos o desenvolvimento da sequência pedagógica na forma de uma história, que o professor conduz e na qual os alunos se envolvem e participam, vemos que, no início, é criado um conflito (o conflito cognitivo ou a questão-problema) a ser resolvido, e que os vários capítulos (as atividades planejadas pelo professor e seus vários momentos de intervenção) devem encaminhar a resolução desse conflito. Contudo, como em toda história, deve haver um capítulo "final" de desfecho (a formalização dos conhecimentos), e esse capítulo, necessariamente, cabe ao contador da história. Mas como o desfecho pertence à história, deve estar intimamente conectado a ela e quem deve ser capaz de perceber alguma conexão é o aluno-ouvinte. Exatamente como manter essa pertinência foi a chave da questão. 
O que pensam os professores sobre a função da aula ...

\section{Referências}

CONTRERAS, J. Autonomia de professores. São Paulo: Cortez, 2002.

LABURÚ, C. E.; ARRUDA, S. M. Reflexões críticas sobre as estratégias instrucionais construtivistas na educação científica. Revista Brasileira de Ensino de Física, São Paulo, v. 24, n. 4, p. 477-488, 2002.

LAJONQUIÈRE, L. Acerca da instrumentação prática do construtivismo: a (anti) pedagogia piagetiana, ciência ou arte? Cadernos de Pesquisa, São Paulo, n. 81, p. 61-66, 1992.

MACEDO, L. Ensaios construtivistas. São Paulo: Casa do Psicólogo, 1994.

PACCA, J. L. A. O profissional da educação e o significado do planejamento escolar: problemas dos programas de atualização. Revista Brasileira de Ensino de Física, São Paulo, v. 14, n. 1, p. 39-44, 1992.

ZEICHNER, K. Formação de professores: contato direto com a realidade da escola. Presença Pedagógica, Belo Horizonte, v. 6, n. 34, p. 5-15, 2000. 